\title{
ФЕРМЕНТНЫЙ ГОМЕОСТАЗ ПРИ НАРУШЕНИЯХ МИКРОБИОЦЕНОЗА КИШЕЧНИКА У ДЕТЕЙ
}

\author{
(C) Точилина О.А. ${ }^{1}$, Частоедова И.А. ${ }^{2}$ \\ ${ }^{1}$ Лицей естественных наук, Киров; \\ ${ }^{2}$ Кафедра нормальной физиологии Кировского государственного медицинского университета, Киров \\ E-mail: olga.tochilina2016@yandex.ru
}

\begin{abstract}
Проведено исследование ферментативной активности слюны и копрофильтрата у детей раннего возраста с нарушениями микробиоценоза кишечника. Установлено коррелятивное возрастание активности ферментов при нарушениях кишечной микрофлоры, а также перераспределение путей выделения гидролаз из организма, следовательно, нарушения эубиоза кишечника у детей сопровождаются выраженными и стойкими изменениями ферментного статуса. Отмечены межсистемные коррелятивные связи гомеостатических систем. Определение содержания и активности гидролаз в биожидкостях может быть использовано для диагностики нарушений микрофлоры кишечника, а также в качестве критерия эффективности проведенного лечения и восстановления функциональной активности кишечника. При коррекции нарушений микробиоценоза кишечника требуется назначение энзимотерапии, корректирующей ферментный гомеостаз.
\end{abstract}

Ключевые слова: амилаза, щелочная фосфатаза, слюна, кишечник, нарушения микробиоценоза кишечника.

\section{ENZYMATIC HOMEOSTASIS IN DISORDERS OF INTESTINAL MICROBIOCENOSIS OF CHILDREN Tochilina O.A. ${ }^{\text {, }}$, Chastoyedova I.A. ${ }^{2}$}

${ }^{1}$ Lyceum of Natural Sciences, Kirov; ${ }^{2}$ Department of Physiology of Kirov State Medical University, Kirov

The research of the enzymatic activity of saliva and coprofiltrate in children of early age with disorders of intestinal microbiocenosis was performed. We have established the correlative increase in the activity of enzymes in disorders of intestinal microflora and the redistribution of ways of secreting hydrolases from the body; therefore the disturbances of eubioz in the intestines of children are accompanied by the expressed and persistent changes in enzyme status. The intersystem correlative connections of homeostatic systems are marked. The determination of the hydrolase content and activity in biological liquids can be used to diagnose the intestinal microflora disorders as well as a criterion of effectiveness of both the treatment conducted and the functional recovery of the intestine. The correction of intestinal microbiocenosis disorders requires the administration of enzymatic therapy to correct the enzymatic homeostasis.

Keywords: amylase, alkaline phosphatase, saliva, intestine, disorders of intestinal microbiocenosis.

Энзимологические аспекты онтогенеза тесно связаны с проблемами роста и развития ребенка. Ферменты играют основную роль в поддержании гомеостаза организма. Гомеостаз достигается сбалансированностью процессов инкреции ферментов с их экскрецией, связью с ингибиторами и протеолизом. При изменении нормальной жизнедеятельности организма возможно возрастание роли других путей перераспределения ферментов и изменение соотношения между ними.

Слюна является легкодоступной биологической жидкостью, ее белковый состав во многом идентичен сыворотке крови и физиологически связан с гомеостазом [4]. Слюнные железы включены в сложно регулируемую систему поддержания относительного постоянства содержания гидролаз в крови, а активность ферментов слюны изменяется в зависимости от состояния ЖКТ и организма в целом. Так, увеличение активности слюнной амилазы отмечают при стоматитах, паркинсонизме, уменьшение - при психическом возбуждении или депрессии, при анацидном состоянии желудочной секреции $[5,6]$. В настоящее время остаются малоизученными изменения состава слюны при различных патологических состояниях, протекающих латентно, таких как изменения состава и функциональной активности микрофлоры кишечника.

В кишечнике помимо пищеварительной функции (переваривание и всасывание нутриентов), также происходит инактивация, рекреция и экскреция пищеварительных ферментов (амилазы, щелочной фосфатазы). Кишечник, наряду со слюнными железами и почками, является мощным вспомогательным путем экскреции ферментов из организма, тем самым участвуя в гомеостатировании гидролаз. Становление процессов разрушения ферментов происходит к 3-4-летнему возрасту [2]. Кроме того, в кишечнике происходит инактивация ферментов при участии нормальной микрофлоры.

В организме развиты прямые и опосредованно нервно-гуморальные связи, из-за которых при заболевании одного из органов могут развиваться нарушения функции в других [3]. Так, и на изменение функционального состояния организма, 
кишечник реагирует изменением содержания ферментов в кале [7]. Исследования последних лет вызывают интерес клиницистов к определению ферментативной активности биожидкостей при различных физиологических и патологических состояниях [1].

Цель исследования - оценить ферментативную активность слюны и кала у детей раннего возраста с нарушениями микрофлоры кишечника, изучить возможные межсистемные коррелятивные связи данных гомеостатических систем.

\section{МАТЕРИАЛЫ И МЕТОДЫ ИССЛЕДОВАНИЯ}

Под наблюдением находились 40 детей раннего возраста (с 1 года до 3 лет), в анамнезе которых имели место кишечные инфекции, острые респираторные заболевания и назначение по этому поводу антибиотиков. Дети с эубиозом составили группу сравнения в количестве 25 человек практически здоровые дети.

Анализ кала на дисбактериоз (выявление аэробных и анаэробных микроорганизмов кишечника) проводился по методике Р.В. ЭпштейнЛитвак и Ф.Л. Вильшанской. При обследовании детей руководствовались требованиями приказа № 231 Минздрава России от 09.06.2003 (ОСТ 91500.11.0004-2003 «Протокол ведения больных. Дисбактериоз кишечника»).

Активность $\alpha$-амилазы определялась ферментативным колориметрическим тестом с 4,6этилиден $\left(\mathrm{G}_{7}\right)$-р-нитрофенилом $\left(\mathrm{G}_{1}\right)$ - $\alpha, \mathrm{D}$-мальто-

гептозидом (этилиден- $\left.G_{7} П Н Ф\right)$ в качестве субстрата (реактив фирмы «Biocon»). Активность щелочной фосфатазы определяли колориметрическим тестом с использованием р-нитрофенилфосфата в качестве субстрата в глициновом буфере (Бессей, Лоури, Брок, 1946). Для определения был использован биохимический анализатор «Cobas Mira Plus» фирмы «Roche».

Статистическая обработка данных осуществлялась с помощью статистического пакета Statistika 6.0. Критический уровень значимости (p) при проверке статистических гипотез принимался за 0,05 . Проверка на нормальность распределения измеренных переменных проводилась по критерию Shapiro-Wilk. В случае нормального распределения переменных применялся параметрический метод по Стъюденту, при ненормальном распределении - непараметрический критерий Манна-Уитни. Корреляционный анализ параметров проведен с учетом ранговой корреляции по Спирмену.

\section{РЕЗУЛЬТАТЫ ИССЛЕДОВАНИЯ И ИХ ОБСУЖДЕНИЕ}

Группу сравнения составили 25 практически здоровых детей раннего возраста, амилолитическая активность слюны которых в пределах нормальных значений составляла 4767,0 481,8 Ед/л,

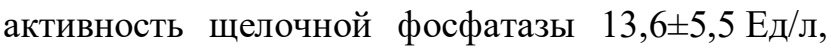
уровень указанных ферментов в копрофильтрате $3380,0 \pm 610,0$ Ед/л и 2606,5 1110,1 Ед/л соответственно. Условно эти значения были приняты за показатели для сравнения с уровнем указанных ферментов у обследованных детей с нарушениями микробиоценоза кишечника.

У $100 \%$ обследованных детей $(\mathrm{n}=40)$ были выявлены нарушения микробиоценоза кишечника I степени - у $42 \%$, II степени - у 55\%, III степени - у $3 \%$, у данной группы детей мы провели исследование гидролаз в динамике наблюдения за энтеральным гомеостазом ферментов. При этом наблюдался дефицит бифидобактерий в $62,5 \%$ случаев $(\mathrm{p}<0,01)$, лактобактерий - в $27,5 \%$ $(\mathrm{p}<0,01)$, в $27,5 \%$ случаев отмечался рост количества $E$. coli с измененными ферментативными свойствами (гемолизирующая кишечная палочка) $(\mathrm{p}<0,05)$. В факультативной части микробиоценоза отмечалось превышение нормального уровня некоторых УПМ: бактерий рода Clostridium у $30 \%$ обследованных ( $<0,01)$, бактерий $S$. aureus в $17,5 \%$ случаев $(\mathrm{p}<0,01)$, у $22,5 \%$ обследованных были обнаружены высокие титры грамотрицательных представителей УПФ (Proteus, Citrobacter, Enterobacter, Alcaligenes и др.) $(\mathrm{p}<0,01)$.

Анализ дисбаланса ферментативного состава слюны у обследованных детей раннего возраста $(\mathrm{n}=40)$ показал достоверное повышение активности амилазы слюны $21935,2 \pm 1568,9$ Ед/л, $(p \leq 0,05)$ (рисунок 1). Щелочнофосфатазная активность

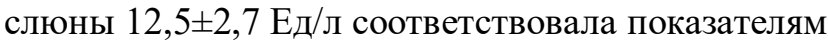
сравнения (рисунок 2). Слюнные железы тонко реагируют на изменения функционального состояния организма, связанные с нарушениями кишечного биоценоза, что приводит к увеличению активности ферментов.

Ферментативный анализ кала обследованных детей раннего возраста $(\mathrm{n}=40)$ также показал повышение активности кишечной амилазы $13418,1 \pm 2681,0$ Ед/л (рисунок 3). Повышение уровня амилазы в кале обусловлено как дисбалансом состава микрофлоры и нарушением инактивации гидролаз, так и изменениями в слизистой структуре кишечника, воспалительными явлениями и как следствие повышенной десквамацией клеточного эпителия. Кроме того, амилаза кала может иметь и бактериальное происхождение. 


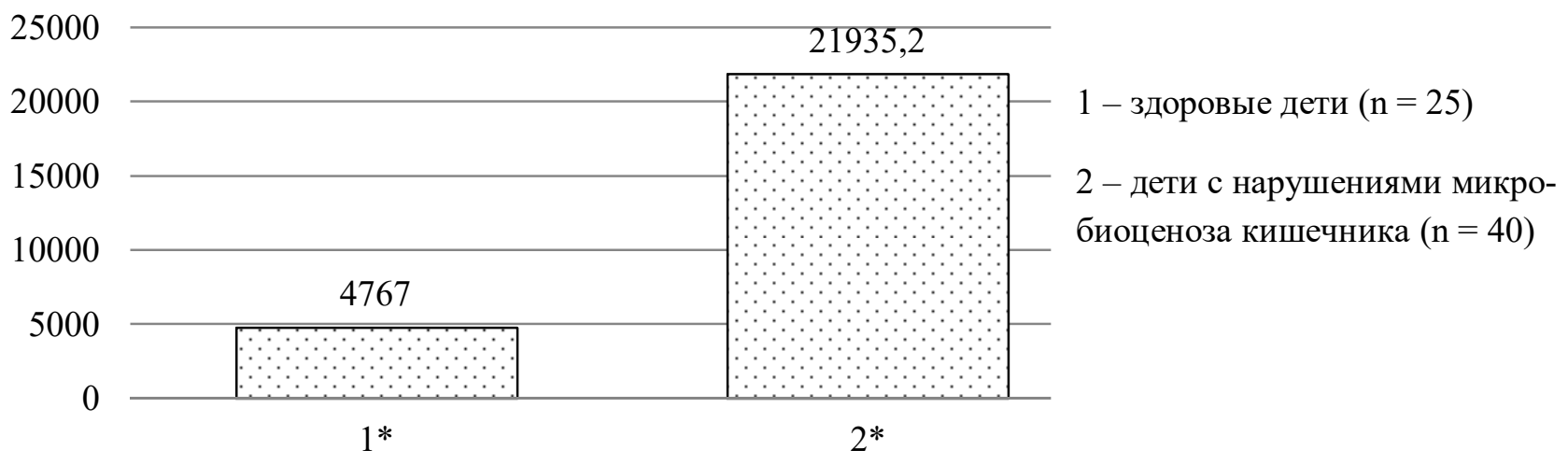

Рис. 1. Активность амилазы слюны (Ед/л).

Примечание: * $-\mathrm{p} \leq 0,05$ при сравнении результатов групп

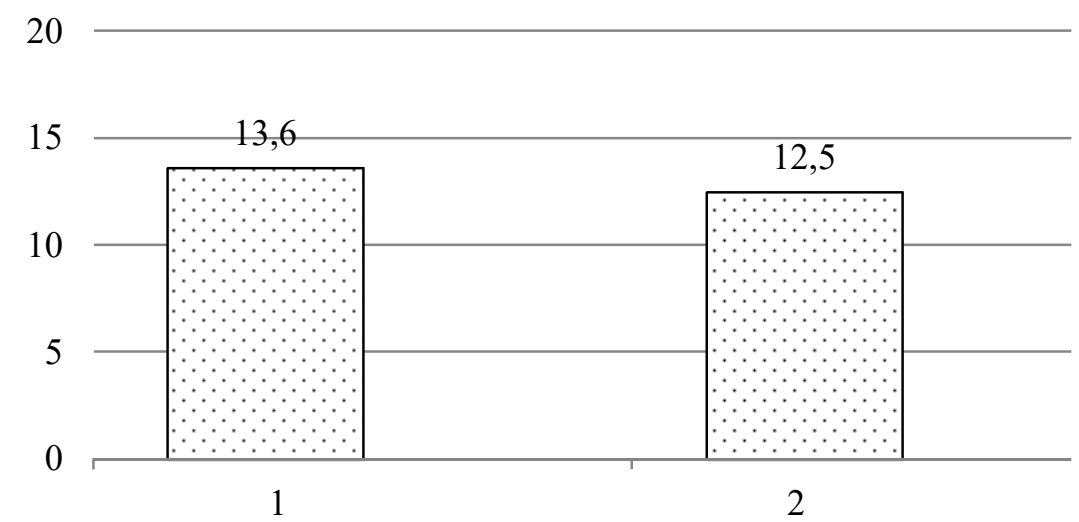

1 - здоровые дети $(\mathrm{n}=25)$

2 - дети с нарушениями микробиоценоза кишечника $(\mathrm{n}=40)$

Рис. 2. Активность щелочной фосфатазы слюны (Ед/л).

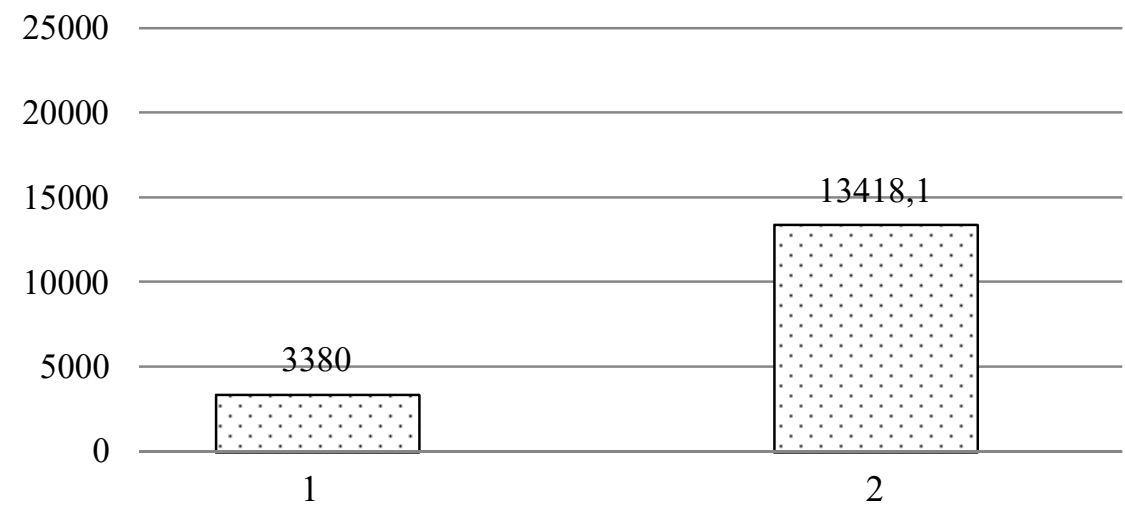

1 - здоровые дети $(\mathrm{n}=25)$

2 - дети с нарушениями микробиоценоза кишечника $(\mathrm{n}=40)$

Рис. 3. Активность амилазы копрофильтрата (Ед/л).

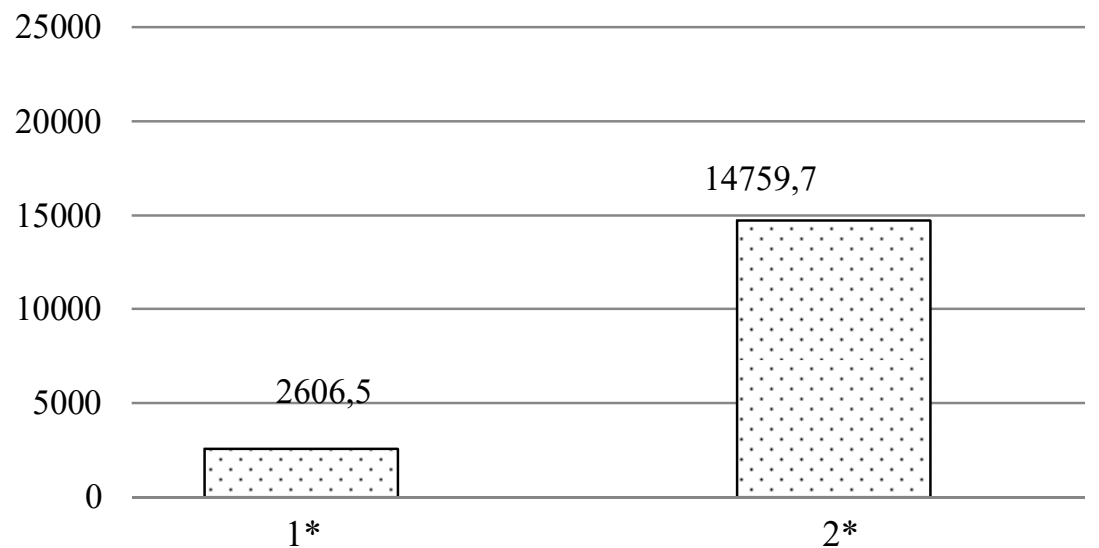

1 - здоровые дети $(\mathrm{n}=25)$

2 - дети с нарушениями микробиоценоза кишечника $(\mathrm{n}=40)$

Рис. 4. Активность щелочной фосфатазы копрофильтрата (Ед/л).

Примечание: * - $\leq 0,05$ при сравнении результатов групп. 
Проведенные исследования выявили повышение активности щелочной фосфатазы в кале обследованных $14759,7 \pm 2248$ Ед/л, $(p \leq 0,05)$ (рисунок 4). Следует отметить, что инактивация энзимов в толстой кишке у детей раннего возраста выражена слабо, с калом выделяется большое количество панкреатических и кишечных ферментов, а нарушения деятельности нормальной микрофлоры при дисбиотических изменениях тормозят расщепление и реабсорбцию щелочной фосфатазы.

В целом наблюдалась повышенная экскреция ферментов как слюной так и кишечником, что отражает воспалительные процессы в кишечнике и подтверждает непосредственную взаимосвязь функционального состояния пищеварительных желез с процессами метаболизма, нарушение которых имеет особое значение в генезе любого заболевания. Полученные данные соответствуют результатам работ Н.Ф. Камакина, И.А. Частоедовой и соавторов в вопросах изучения функциональной активности пищевариетльных ферментов при патологии желудочно-кишечного тракта [1].

Корреляционный анализ ферментативного спектра выявил прямую зависимость между амилазой и щелочной фосфатазой слюны $(r=0,328$, при $\mathrm{p}=0,038)$. Также отмечены межсистемные коррелятивные связи гомеостатических систем: амилаза и бифидобактерии ( $\Gamma=-0,461$, при $\mathrm{p}=0,009)$.

Таким образом, нарушения эубиоза кишечника у детей сопровождаются выраженными и стойкими изменениями ферментного статуса, при этом наблюдается перераспределение путей выделения гидролаз из организма. Межсистемные коррелятивные связи указывают на вероятное возрастание напряженности углеводного метаболизма при нарушении микробиоценоза кишечника, что приводит к сопряжению работы ферментных систем и микробного гомеостаза.

Определение в кале содержания и активности гидролаз может быть использовано для диагно- стики нарушений микрофлоры кишечника, а также в качестве критерия эффективности проведенного лечения и восстановления функциональной активности кишечника. А при коррекции нарушений микробиоценоза кишечника требуется назначение, кроме базового лечения, энзимотерапии для коррекции ферментного гомеостаза.

\section{ЛИТЕРАТУРА}

1. Камакин Н.Ф., Частоедова И.А., Григорович М.С., Лопатина Л.А. Функциональная активность пищеварительных ферментов при патологии желудочно-кишечного тракта с нарушением микробиоценоза кишечника // Вопросы питания. - 2012. T. 81, № 4. - C. 53-57.

2. Куваева И.Б., Ладодо К.С. Микроэкологические и иммунные нарушения у детей. - М. : Медицина, 1991. - $240 \mathrm{c}$.

3. Литюшкина М.И. Активность кишечных ферментов у больных с осложненным течением язвенной болезни // Вестник новых медицинских технологий. - 2008. - Т. XV, № 2. - С. 73-75.

4. Сухарев Т.Н., Ермолаева Н.А., Беда В.Ю., Тегза В.Ю. Организация иммунохимических исследований лактоферрина в слюне для оценки состояния здоровья // Новые технологии, методы диагностики, лечения, профилактики. - 2008. - № 4 (29). - C. 81-84.

5. Тохунец Э.К. Активность фосфатаз в слюне при начальных формах поражения пародонта // Медицинский вестник Эребуни. - 2009. - № 2. C. 71-75.

6. Шилькиева И.А., Кондратенко Е.И., Горст Н.А. Оценка адаптационных процессов организма по показателям ферментативной активности слюны у первоклассников // Естественные науки. - 2011. № 3 (36). - С. 142-146.

7. Частоедова И.А., Точилина О.А. Оценка рациона питания и ферментовыделительной функции у детей раннего возраста с дисбактериозом кишечника // Вятский медицинский вестник. - 2011. № 3-4. - С. 50-53. 